\title{
Contemporary Clothing Habits and Sexual Behaviour of Adolescents' in South Western Nigeria
}

\author{
Olugbenga David Ojo and Odeleye Bidemi* \\ National Open University of Nigeria, 14/16, Ahmadu Bello Way, Victoria Island Lagos, Nigeria \\ *Department of Counselling Psychology, Tai Solarin University of Education, Ijagun, \\ Ijebu-Ode, Nigeria
}

KEYWORDS Adolescents. Sexual Behaviour. Contemporary Clothing Habit

\begin{abstract}
Adolescence period is characterised by various incidences. This allows for confirmed inferences of different magnitude. This study looked into contemporary clothing habits and sexual behaviour of adolescents in the South Western Nigeria with a view to establish whether there is a relationship between adolescents' clothing habits and their sexual behaviour and also, what influences their clothing habits. 520 adolescent students were randomly selected using quota-sampling method from available higher institutions in the South Western Nigeria. Clothing Habits and Sexual Behaviour Questionnaire (CHSBQ) was used to collect data, which was analysed by t-test statistics inference at a 0.05 level of significance. The result shows that there is no significant difference in the factors influencing adolescents' dressing habits and also the fact that there is relationship between clothing habits and their sexual behaviour.
\end{abstract}

\section{INTRODUCTION}

In the history of fashion and costumes, there is always a reason why cloth is worn. In man's early history, he wore clothes simply to keep warm, and the materials available - animal skins and furs then determined kinds of cloth. For example, Ice Age cave dwellers wore animal skins for extra warmth as some Inuit (Eskimo) hunters and Laplander reindeer herders still do - while many native African people wore and still wear very little. Then, if a man wore a lion's skin, you could be sure he was a brave hunter. Tribal chiefs liked to wear something (a crown, a hat or a cloak of a special colour, perhaps) which no one else was allowed to have or wear.

Adolescents and young adults have long recognised the significance of clothing. To signal, connectedness and to distinguish themselves from others, groups of young people adopt styles of dress that express their particular distinct identity. Hebdige (1979) and Odeleye (2000) observed that in making clothing choices, adolescents are demonstrating awareness that a style or mode of appearance has meaning. Rowland-Warne (1992) also corroborated this by asserting that clothing in any culture is a means of communication. This assertion, point to the fact that clothing conveys messages when members of a society who share a given culture have learned to associate types of clothing given customary usage. Through this customary association, certain types of clothes become symbols of mood, social role, socio-economic status or political class.

In the recent time, it has been observed that a change is occurring in the mode of dressing and clothing style of the adolescents. This change as observed is noticed both in the rural and the urban area of the society. It is a common knowledge that with respect to our Yoruba culture in the Western Nigeria, the mode of dressing and clothing is such that a young woman wears iro, buba and gele while the young man puts on buba, sokoto and fila. The observed little change or shift noticed in the past has the incursion of European mode of dressing brought about by the colonization of the Nigerians by the Whites which made young woman to wear skirts and blouse or gown while young man clad in a combination of shirt and trousers. But amongst the adolescents, there is now a new mode of dressing and clothing. The adolescents are desperately veering from the past mode of dressing be it the original Yoruba mode of dressing or the type of dressing brought about by colonization. The adolescents' way of dressing has departed totally from the past. They dress weirdly and embarrassingly. The female adolescents mostly dresses half nude; they prefer to wear trousers and skimpy shirts or tee-shirts that reveals their tummy, body hug which shows all the contours in their body frames or mini-skirt with a see - through tops while the boys although 
still wears shirt and trousers but which are always in various bigger sizes compared to their nominal sizes. This observed clothing habit is not limited to a specific class of adolescents. It cut across the entire socio-economic status, irrespective of their educational level and status.

This, has been going on for quite some time and therefore what used to be regarded as fashion which is described to be a period's desired appearance (Odeleye 2000) is being turned to clothing which is regarded as an established patterns of dressing (Rubinstein, 1995)

However, looking at the modern day clothing habits and the adolescents' sexual behaviours, one may tend to conclude that the former is an encourager of the former and also that it is the relationship between the two that is entrenching this fashion as clothing habits among the adolescents. The adolescents' sexual behaviour in the past few years has been a source of concern to many parents and researchers. Adolescents' have been confirmed to be involved in series of sexual activities ranging from premarital sexuality (NDMA,1990) or Coitus experimenting (Odujinrin, 1991), multi-sexual partners (Oronsaye and Odiase, 1983), heterosexual breast stimulation and genital stimulation (Schoofied, 1967, Ojo 2000) which always lead to adolescent pregnancy (Akingba, 1977; Makinde, 1978), abortion (Fasubaa, 1996; Okonofua, 1996; Fasubaa and Ojo,2004) teenage maternal mortality (Abiodun, 1984), sexually transmitted diseases (Okonofua and Kaufman, 1995) and contracting of Acquired Immune Deficiency Synndrome-AIDS (Eshiet, 1995).

The research therefore aims at investigating the factors that influences the clothing habits of adolescents' and the impact which dressing habits have on the sexual behaviour of the adolescents and also establish the relationship between clothing habits and sexual behaviour with a view to determine whether clothing is an extension of human personality, and if so, consider its implication for psychological development and adolescents' behaviour counseling.

\section{Research Questions}

(1) What are the factors influencing the adolescent clothing habit?

(2) Is there relationship between the adolescents clothing habit and adolescents sexual behaviour?

(3) Do the perception of the relationship between the adolescent's clothing habits and adolescent's sexual behaviour among males and females tally?

\section{Research Hypotheses}

(1) There will be no significant difference in the perception of male and female adolescents as regard the factors influencing clothing habits of the adolescents

(2) There will be no significant difference in the perception of male and female adolescents as regards the relationships between the adolescents clothing habits and adolescents sexual behaviour

\section{METHODOLOGY}

The descriptive survey method was used for this study. The sample for the study consisted of male and female adolescent students from Nigeria higher institutions located in the Southwestern Nigeria. The students were drawn by quota sampling method from Osun State College of Education, Ilesa, Obafemi Awolowo University, Ile-Ife, Ibadan Polytechnic, College of Education, Ondo, Federal Polytechnic, Ilaro and Lagos State University, Lagos. A total of 100 students who were in either part II or III were selected from each institution.

This was done by a random distribution of questionnaires in the schools of education (Ilesa and Ondo), faculties of Law, Agriculture and Science (O.A.U) and Social Sciences and Commerce - Banking, Finance, Marketing and Insurance (Ibadan and Federal Polytechnic, Ilaro) and Arts and Administration (Lagos State University).

The questionnaires was a simple paper and pencil type and were administered by the investigators assisted by lecturers, who were teaching large classes in parts II and III in each of the institutions used for the study. The questionnaires were administered and collected immediately. Thus, the total subjects that participated in this study were 600 but the Questionnaires found usable were 520. This was made up of 346 female adolescents and 174 male adolescents. 80 were discovered because they were badly completed.

Instrument: The research instrument Clothing Habits and Sexual Behaviour Questionnaire (CHSBQ) used for this study was designed by 
the researchers. It has two sections. Section A was designed to collect demographic data such as sex, age, religion, level of education of parents and the marital status (divorced, separated or intact) of parents. Section B consisted of 15 fourpoint Likert type items, which were made to reflect the focus of study. The subjects were required to respond to each item by choosing whether Strongly Agreed (SA), Agreed (A), Disagreed (D) and Strongly Disagreed (SD).

The instrument was validated by expert in Test and Measurement in the Faculty of Education, Obafemi Awolowo University, Ile-Ife while the reliability of the questionnaire was determined by the use of test re-test method using twenty part II adolescent students of the Faculty of Education, Obafemi Awolowo University, Ile-Ife. The re-test was done after a two-week interval. The coefficient was found to be equal to 0.62 and significant at 0.05 level of significance.

Scoring: Each respondent was rated numerically from $1-4$ on each item. Arespondent who say "Strongly disagree" to a negative item obtains a high score (4) just as he does when he say "strongly disagree" to positive statement which attracts a score of 1 . A response of "strongly disagree" to a positive statement attracts to the same scoring process as above.

Data Analysis: The two hypotheses raised for the study were tested and analysed. For the hypotheses, t-test inferential statistics was employed in order to establish whether there is significant difference between the drawn means. Based on the t-test data, null hypotheses were rejected or accepted at 0.05 level of significance.

\section{RESULTS}

Hypothesis 1: This stated that there would be no significant difference in the perception of male and female adolescents as regards the factors influencing clothing habits of the adolescents. The scores of the 346 female adolescents and 174 male adolescents were collated and analysed using ttest statistics for comparison of their means.

Hypothesis II: This stated that there would be no significant difference in the perception of male and female adolescents as regards the relationship between the adolescents' clothing habits and adolescents' sexual behaviour.

The null hypothesis comparing female and male adolescents is accepted. The t-calculated (1.48), $\mathrm{df}=518, \mathrm{P}>0$ is smaller than the t-value. Therefore, there is no significant difference in the perception of adolescents as regards factors that influences the clothing habits of the adolescents.

The null hypothesis is accepted. The tcalculated value (1.36), $\mathrm{df}=518, \mathrm{P}>0.05$ is smaller than the t-value. This confirms that there is no significant difference in the perception of male and female adolescents as regards the relationship between the adolescents clothing habits and adolescents sexual behaviour.

\section{DISCUSSION}

The result of the data analysis for the first hypothesis indicates that there is no significant difference in the perception of male and female as regards the factors that influences adolescent clothing habits. It confirms that the two sexes clothing habits are influenced by the same factors. Both the male and female adolescents acceded to influencing factors such as social approval, anxiety, and exhibitionism and modernity as the factors that influence their clothing habits.

The two sexes desire social approval of what they put on although female adolescents may

Table 1: t-test of Difference in Perception of Adolescents as regards factors influencing Clothing Habits.

\begin{tabular}{lccccc}
\hline Adolescents & $N$ & $X$ & $S D$ & $D f$ & $t$-cal \\
\hline Male & 174 & 37.81 & 27.36 & 518 & 1.48 \\
Female & 346 & 39.62 & 29.75 & & NS
\end{tabular}

NS: Not significant at $\mathrm{P}>0.05$

Table 2: t-test of difference in perception of male and female adolescents as regards the relationships between the adolescents dressing habits and sexual behaviuor

\begin{tabular}{lcccccc}
\hline Adolescents & $N$ & $X$ & $S D$ & $D f$ & $t$-cal & $t$-crit \\
\hline Male & 174 & 77.58 & 4.10 & 518 & 1.36 & NS \\
Female & 346 & 80.02 & 3.86 & & & \\
\hline
\end{tabular}

NS: Not significant at $\mathrm{P}>0.05$ 
incline to their gender native and formation. The two sexes are not also anxious about whatever they put on. They are not anxious to conform to the clothing habits of their culture but are anxious to put on latest in vogue dresses. They regarded the cultural clothing styles to be archaic. They are ready to exhibit themselves and what they have without being bothered by the originality of the clothing style provided that what they put on is the current styles in the western world (thanks to western films, Nigerian travelers, the Internet, and CNN; Style: a clothing exhibition programme which is regarded as an outlet for people to be aware of modern day clothing trend). Female adolescents like male adolescents now wear trousers of different shapes, colours and sizes. They prefer wearing trousers and skimpy dresses to skirts and gowns, which are regarded as ladies wear from time immemorial. These days when gown or skirt is worn, it will either be a mini length dress or body hug (tight) that will reveal their legs or the natural curves and shapes of their bodies.

The result of the second hypothesis shows that there is no significant difference in the perception of both male and female adolescent as regards the relationship between adolescents clothing habits and their sexual behaviour. This, thus confirm that the adolescents themselves are aware of the fact that the current kind of dressing habit and styles they regarded as fashion exposes them to opposite sex and also ignite and encourage libidinous (libido) intentions. Looking at the sexual behaviours of the adolescents, several studies have confirmed the high incidence of premarital sexuality among unmarried youth (Feyisetan and Pebley 1989), Makinwa Adebusoye, 1991: Odujurin, 1991; Owuamamam, 1982; Oyeneye and Kawonise, 1993). Other variations in foreplay and coitus such as kissing, breast / genital fondling (Owuamaman, 1982; and Diephold and Young, 1979; Alzate, 1977, Soyinka, 1979 and the high prevalent rate of adolescent pregnancies and contracting of sexually transmitted diseases including HIV/AIDS (Okonofua, 1996; Fasubaa, 1995; Ojo, 2000; Eshiet, 1995) a resultant effect of unprotected sexual activity of the adolescents. Evidence from the 1990 Nigeria Demographic Health Survey (NDHS) has not only confirmed the high incidence of all these adolescents' behaviours and happenings in urban centres, it also revealed that the incidences are not only limited to urban centres, but that rural areas are now inclusive. Considering the relationship of intent between the current dressing habits of adolescents and the confirmed sexual behaviour, it could be infer that it is the un-waiver high incidences of adolescents' sexual behaviours that encourage the kind of dressing habits the adolescents now display. It may also be vice versa. This, therefore connote that the re is relationship between the adolescent dressing habits and their sexual behaviour. One could be regarded as the resultant effect of the other, that is, sexual habits can be considered as the resultant effect or the end product of the dressing habits. The adolescents' kind and mode of dressing is out to entice and arouse the opposite sex for sex and other related sexual behaviours irrespective of whatever opinion they have about it. This inference, tally with Carlyle (1967) assertion that clothing style and signs make visible the structure and organisation of interactions with a specific social context. Odeleye (2000) remarked that the first non-verbal message a person clad in black shirt and black trousers passes is death, or rather mourning. He also asserted that differentiating the sexes, and arousing sexual interest are facilitated by the employment of categories of clothing signs. Respondents' responses to some items in the questionnaire show the feelings and thought of adolescents as regards their clothing style, type and habits. $482(92.7 \%)$ strongly agreed to 'dressing to attract the attention of the opposite sex is only proper', $474(91.1 \%)$ strongly agreed to 'there is nothing offensive in exposing part of the body' $470(90.4 \%)$ agreed to 'I would do anything to wear the latest fashion in vogue', $418(80.4 \%)$ agreed to 'dressing up is a major hobby in my life' and $461(88.7 \%)$ also agreed to "it does not matter to me what others feel about my dressing”. Also, 396 (76.2\%) strongly agreed to 'I dress to please my admirers' while 402 (77.3\%) and $417(80.2 \%)$ respectfully agreed to 'I like to show off whatever I am wearing' and 'flashy designs are my choice when it comes to clothes'. These high positive responses also go for the item that says 'Dressing to attract the attention of the opposite sex is proper' and 'It does not matter to me what others feel about my way of dressing'.

Conclusively, the item-by-item analysis of the respondents' response to some items from the questionnaire has virtually corroborated the inference drawn as regards the establishment of relationship between clothing habits of adole- 
scents and their sexual behaviour. This further confirmed the fact that there is relationship between the two variables. This, thus reinstate the fact that clothing habits depict partly the kind of behaviour and attitude a person could exhibit at any time and that clothing is an extension of personality since it is possible to infer the kind of person one is from one's attitude and dressing habit. Candidly, there is nothing wrong in dressing the way one wants but sanity and moral justification should be parts of the variables to be considered along with ones culture when putting on some attitudes. There should not be any agitation if a young Briton lady or an American lady dresses according to the dictate of her culture with the hindsight of her weather but it will be abnormal for a young African lady to dress in contrary to the dictate of her culture and without respect for the weather in the name of fashion and vogue.

The implication of the results of the study is that there is tendency for increase in the rate of adolescent rape and pregnancy and also contracting of infections and HIV/AIDS apart from other sexual behaviours. The mode of dressing of the adolescents is an open invitation to these repercussions. In other to reduce and avert the resultant effect of these dressing habits, it would be recommended that government; parents and school authorities should act decisively towards stopping the continued growth of all attitudes and behaviours that increases the immoral behaviours among the adolescents. Some of these clothing habits and what they portray is alien to our culture. Our culture does not support nudity or flaunting of bodies as if it is a product that is being put up for sale. Nudity does not only attract men, but also rapists. Good dressing is regarded as a cultural value. In this side of traditional setting, women who go to fetch water from the streams are not allowed to leave their hair uncovered, young girls are taught to sit properly early in their upbringing. Women do not climb palm trees and women do not throw their legs anyhow while men do not just cross the legs of women. This is sufficed to say that modernity is not a license for young girls and women to feel they are free to dress anyhow. Dressing codes should be introduced to the tertiary institutions while dressing style specifications should be adopted at the postprimary institutions where style and kind of uniform are dictated. Schools should teach family life education that is all encompassing as a compulsory subject in schools and government should orientate the whole public on the need to be wearing body friendly clothes instead of uncomfortable, tight-fitting types as presently worn by adolescents and some elders. Lastly, guidance counselors should be employed in both the post-primary institutions and the higher institutions available in the southwestern Nigeria. These professionals in all ramifications have a lot to contribute to the personality growth and development of the youths in the school settings. They have a lot to offer if they are properly equipped to function effectively and efficiently. They will assist in helping out adolescents in schools.

\section{REFERENCES}

Abiodun E.A.: Sexual Attitudes of Adolescents in Ondo State Secondary Schools: Implications for Counseling. An Unpublished Ph.D. Thesis. Faculty of Education, Department of Foundations and Counselling, University of Ife (1984).

Akingba, J.B.: Some Aspects of Teenage Pregnancy and Abortion in some Nigerian Adolescents. Paper presented at the World Heath Organization meeting on Pregnancy and Abortion in Adolescence, Geneva June 24 - 28 (1977).

Alzate, H.: Sexual Behaviour of Columbia Female University Students. Archives of Sexual Behaviour 7(1): 43-53 (1977).

Carlyle, T. Sartor Cesartus. Dutton (Originally published in 1838) New York (1967).

Diepold, J. and Young, R.D.: Empirical Studies of Adolescents Sexual Behaviour: A critical Review Adolescence 16(53): 45-64 (1979).

Eshiet, O.O.: Are your At Risk of Pregnancy, STD/HIV and Death? Growing Up, (1): 1-2 (1995).

Fasubaa,O. B. Post-Abortion Contraception in Southwestern Nigeria. A paper presented at the International Conference on Abortion in Amsterdam, Neitherlands. March (1995).

Fasubaa, O. B. and Ojo, O. D.: Impart of Post-abortion Counselling in a semi-urban town of Western Nigeria, Journal of Obstetrics and Gynaecology, 24(3): (2004)

Feyisetan, B and Pebble, A.R.: Premarital Sexuality in Urban Nigeria. Studies in Family Planning, 20: 343 - 354 (1998).

Hebdige, D.: Subculture: The Meaning of Style. Methuen, New York (1979).

Makinde, O. Samples of a Nigerian University Community Grattiti: Implications for Counseling. Ife Journal of Educational Studies 1(1): 17 - 26 (1978).

Makinwa - Adebusoye: Sexual Activity of Adolescents in Youth and Reproductive Health in Africa. An Annotated Bibliography on Adolescent Reproductive Heath. UNFPA Nigeria (1991).

Odeleye, A.D.: Psychological Correlates of Contemporary Clothing Behaviour of Nigerian Undergraduate Students. An Unpublished Ph.D Thesis, Faculty of 
Education, Department of Foundations and Counselling, Obafemi Awolowo University, Ile-Ife, Nigeria (2000).

Odujinrin, O.M.: Sexual Activity, Contraceptive Practice and Abortion Among Adolescents in Lagos, Nigeria: International Journal of Gynaecology and Obstetrics, 34(4): 361 - 366 (1991).

Ojo, O.D.: Knowledge, Attitudes and Practices of Parents and Teachers in Relation to Adolescents Reproductive Health Training in Osun State, Nigeria. An Unpublished Ph.D Thesis. Faculty of Education, Department of Foundations and Counsell-ing, Obafemi Awolowo University, Ile-Ife, Nigeria (2000).

Okonofua, F.E.: The case against New Reproductive Techniques in Developing Countries. British Journal of Obstetrics and Gynaecology, 20(5): pp 409-412 (1996).

Okonofua, F.E. and Kaufman: Pregnancy Experiences of Unmarried Women and Induced Abortion in Nigeria. Outcome of Robert H. Ebert Sponsored Programme Printed in the Population Council Newsletter (1996).
Oronsaye, A.U. and Odiase, G.T.: Attitude Toward Abortion and Contraception Among Nigerian Secondary School Girls. International Journal of Obstetrics and Gynaecology, 20(5): 409-412 (1983).

Owuamaman, D.O. Sexual Activity of School - going Adolescents in Nigeria. Adolescence, 17(65): $81-$ 87 (1982).

Oyeneye, O.Y. and Kawonise, S.: Sexual Network in IjebuOde, Nigeria: An Exploratory Study. Health Transition Review, (Supplement to Vol.3): 171 183 (1993).

Rowland-Warne, L.: Costume. Alfred a Knopf Inc. New York, United States of America. pp 38- 39 (1992). Rubistein, RP.: Dress Codes: Meanings and Messages in American Culture. Westview Press, Colorado U.S.A. (1995).

Schoofield, M.: The Sexual Behaviour of Young People. Mass. Little, Brown and Company, Boston (1967).

Soyinka, F.: Sexual Behaviour Among University Students' in Nigeria. Archives of Sexual Behaviour, 8(1): 15-26 (1979). 